\title{
Journal of Clinical Care and Skills. 2020;1(2):75-80 \\ Comparison of the Impact of Face-to-face Education and Educational Booklet Methods on Health-related Quality of Life in Patient with Type 2 Diabetes

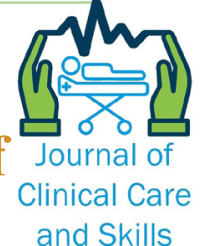

\section{ARTICLE INFO}

\section{Article Type}

Original Research

\section{Authors}

Alamdari A.K. ${ }^{1} P h D$,

Taheri R. ${ }^{1} M S C$

Afrasiabifar A. ${ }^{1} P h D$

Rastian M.L. ${ }^{* 1} M S C$

\section{A B S T R A C T}

Aims Several studies have shown controversy over the effectiveness of various educational methods. This study was performed with the aim of comparing the effect of face-to-face education and educational booklet on health-related quality of life in patients suffering from type 2 diabetes.

Materials and Methods In this study clinical trial study, which was conducted in 2017, 120 patients qualified to enter the study were selected by random sampling; they were randomly allocated to 3 groups, including, face-to-face group, education through booklet, and control group. The data were collected through Diabetes Quality of Life-Brief Clinical Inventory (DQL-BCI). Patients in the two intervention groups were presented with materials with the same educational content, but different teaching methods. The data were analyzed by SPSS 21, using Chi-square, one-way analysis of variance, paired t-test, and Tukey's post hoc test. Findings Before intervention, mean score of health-related quality of life in patients in the 3 groups was not statistically significant $(p=0.1)$. After intervention, there was a significant difference between the mean score of health-related quality of life of patients in intervention groups and control group ( $\mathrm{p}=0.001)$. However, there was no significant difference between the patients in face-to-face and education through booklet groups ( $p>0.05$ ).

Conclusion The effect of face-to-face education and educational booklet on health-related quality of life in patients with type 2 diabetes is the same.

Keywords Face-to-Face Education; Health-Related Quality of Life; Type 2 Diabetes
${ }^{1}$ Nursing Department, Nursing Faculty, Yasuj University of Medical Sciences, Yasuj, Iran

\section{Correspondence}

Address: Nursing Department, Nursing Faculty, Yasuj University of Medical Sciences, Yasuj, Iran. Postal Code: 7591714949 Phone: $+98(74) 33235141$ Fax: +98 (74) 33235141 R115_rastian@yahoo.com

\section{Article History}

Received: August 21, 2018

Accepted: December 3, 2018

ePublished: June 20, 2020

\section{CIT A T I O N LINKS}

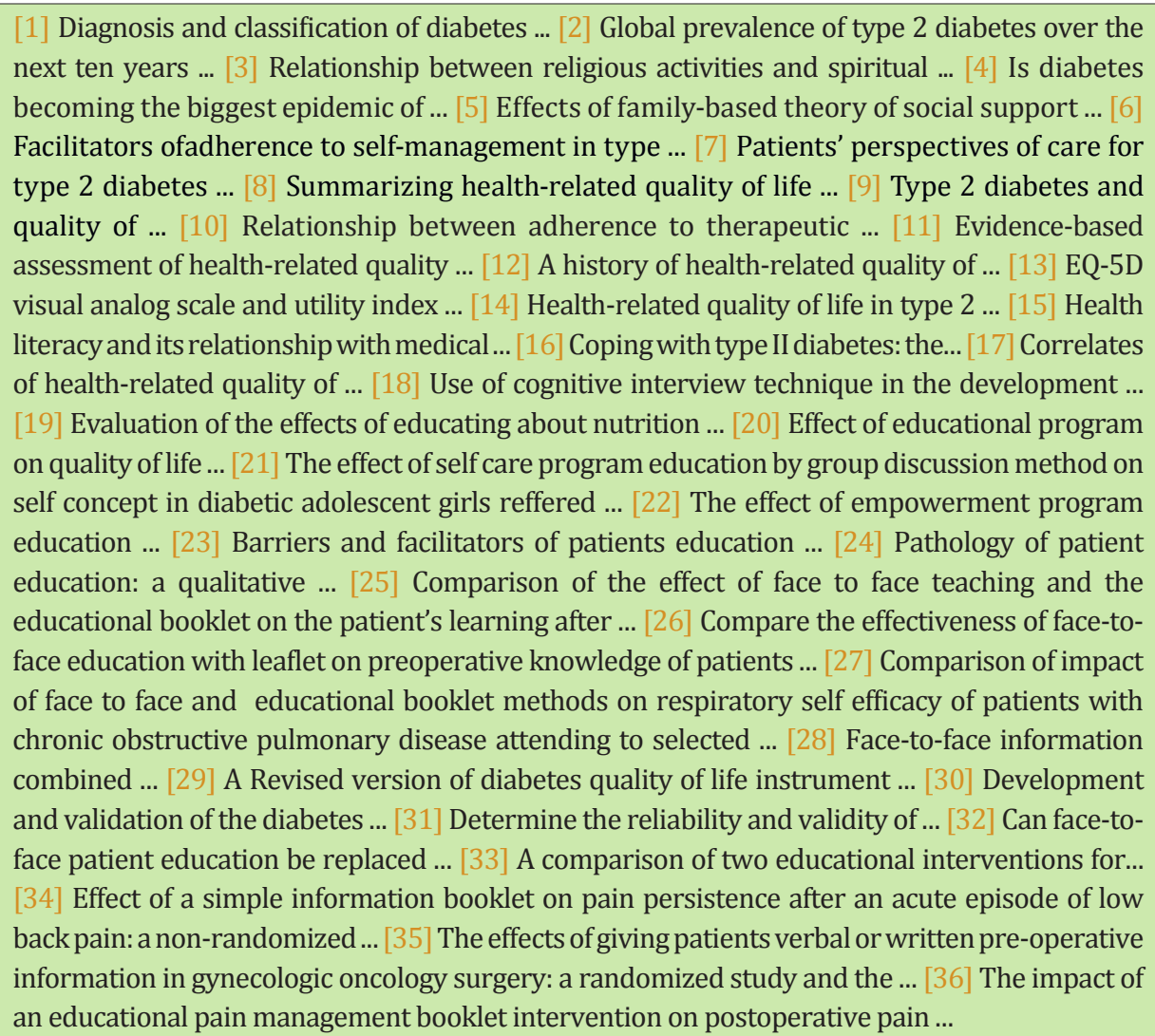




\section{Introduction}

Diabetes mellitus is a metabolic disorder caused by insulin secretion, insulin function, or both [1]. The incidence of diabetes is estimated to be more than 500 million people in 2018 worldwide [2] and 3-5\% in Iran, with 100,000 new cases annually [3]. Diabetes is not only economically costly ${ }^{[4]}$, but also is one of the main causes of blindness, amputation and chronic renal failure [5]. Despite the possible prevention of diabetes complications, inadequate information and high-quality care [7] causes inappropriate control of diabetes, which can considerably affect the quality of life of diabetics ${ }^{[5]}$.

Health-related quality of life is a multidimensional concept commonly used to examine the impact of health status on quality of life ${ }^{[8]}$ and refers to the physical, psychological, and social dimensions of health [9], which is influenced by experiences, beliefs, expectations and perceptions of the individual [10] and is considered as a useful indicator for evaluating general health ${ }^{[11,12]}$.

Several studies have shown that health-related quality of life in people with diabetes is reduced compared with healthy subjects with similar age groups [13-15]. With the advancement of disease and the emergence of complications, changes in lifestyle and the patient's fear of complications, the healthrelated quality of life of diabetic patients is reduced $[13,14,16,17]$.

Education is one of the factors that can affect the change in health behaviors and identification and understanding of patients [18]. Today, education and self-care is more considered than treatment, which helps patients to make their own decisions about their own health [19]. Several studies have shown that training diabetic patients with different educational methods has improved the metabolic status of diabetic patients [20]. In addition, numerous educational methods, such as individual training, group training, group counseling, internet and computer training by nurses have been used to improve self-care behaviors and to improve the health of diabetics [21], the effectiveness of patient education methods depends on their correct design. But Face-to-face or in-person approach is the most common educational method. Despite its several educational advantages, in many situations due to the limited resources, equipment and manpower, it is difficult to use this method, so that other methods should be used [22].

The booklet is a useful tool because it is inexpensive and easy to use for patients and the patient can quickly read the contents and review them at any time. In addition, it reduces the time spent by nurses $[23,24]$. On the other hand, the majority of people learn less than a quarter of what they hear, but if information is provided in writing, the learning sustainability increases significantly [25].

Several studies has reported the effectiveness of various educational methods and different and sometimes contradictory findings [26]; for example, in a study the greater impact of face-to-face education compared with educational booklet on respiratory self-efficacy in patients with chronic obstructive pulmonary disease [27]. However, in another study, in-person training with a booklet was not more effective than the booklet alone for pain management in mild back pain [28]. Also, in another study, there was no difference between the effectiveness of the booklet compared with face-toface verbal training [26].

Therefore, given the contradictions in this field, this study was performed with the aim of comparing the effect of face-to-face education and educational booklet on health-related quality of life in patients suffering from type 2 diabetes.

\section{Materials and methods}

This study is a randomized clinical trial with control group, which was done in Jahrom city in 2017. The study population consisted of all patients with type 2 diabetes who referred to the diabetes clinic of the Jahrom city, who had health records at the health center. This study was approved by the Yasuj University of Medical Sciences Ethics Committee (Ethics code: IR.YUMS.REC.1395.70).

The most important inclusion criteria included a definitive diagnosis of type 2 diabetes by the physician, at least 6 months after diagnosis, the age of over 30 years, obtaining health-related quality of life score at the moderate and unfavorable level based on the questionnaire, no diagnosed psychiatric disorder in the patient, at least reading literacy to attend classes and answering questions, informed consent for participation in the study, no access to similar educational programs from other sources. Exclusion criteria also included unwillingness to continue to participate in the study, no complete answers to the health-related quality of life questionnaire, and no regular participation in educational programs.

The number of needed patients was calculated for 34 subjects in each group by considering the $95 \%$ confidence level, test power of $80 \%$ and based on the formula, and also regarding a falling of $5 \%, 40$ subjects in each group and a total of 120 subjects was considered.

Patients who met inclusion criteria were selected by nonprobability convenience sampling and were selected from the patients referred to the clinic, however, they were assigned by random block allocation to the three education groups, including the booklet, face-to-face training and control groups. Three groups were considered, so in terms of the number of blocks, Factorial was used and the number of blocks was estimated 6 blocks.

Each block size was 3 subjects, but the order of their allocation into the blocks was different, and there 
was one patient was from all three groups in each block. Blocks were selected by allocation to obtain the desired number of patients.

The data collection tool was a demographic questionnaire and the Persian version of the Diabetes Quality of Life-Brief Clinical Inventory (DQOL-BCI). The DQOL-BCI was developed by the Diabetes Control and Complications Trial (DCCT) [29], and its reliability has been confirmed [30,31]. It is a 15 -item questionnaire, which is scored on a 5-point Likert scale from "very unsatisfied" (score 1), "unsatisfied" (score 2), "moderate or sometimes" (score 3), "satisfied" (score 4), and "very satisfied" (score 5). The total score of the questionnaire is obtained by the total score of all questions and varies from 15 to 75 . Higher scores mean better health-related quality of life. In addition, the score of 15-34 shows undesirable health-related quality of life, a score of 35-55 indicates moderate healthrelated quality of life and a score of 56-75 means favorable health-related quality of life. In order to determine the validity, the questionnaire was provided to 20 diabetic patients with inclusion criteria for two times in a 14-day interval and was approved with a coefficient of 0.82 .

For intervention, the two intervention groups received the same educational program using two methods (face-to-face education and educational booklet), and the control group received the clinic conventional educations. Educational program included an explanation of diabetes, treatments, how to use drugs, if necessary insulin therapy, recommendations for the prevention of hypoglycemia and hyperglycemia, training for controlling blood sugar, diet and exercise. In face-toface training group, training was conducted in a separate room in diabetes clinic for 20-30 min for three weekly sessions. The same educational booklets were provided for the patients using simple and understandable illustrations as a booklet to study. Data was collected one week before training and two weeks after training.

The collected data were analyzed by SPSS 21 using descriptive statistics and Chi-square test for comparing demographic variables, one-way ANOVA for inter-group comparison, Paired t-test for intragroup comparison and Tukey's post-hoc test for pair comparison of the groups. It should be noted that Kolmogorov-Smirnov test was used to determine the normal distribution of quantitative data.

\section{Findings}

120 patients with type 2 diabetes, with an average age of $55.55 \pm 13.10$ years (age range: 33 to 77 years) were participated in the study, of whom $27.5 \%$ were male and $72.5 \%$ were female. There was no significant difference in demographic variables between the three groups ( $p>0.05$; Table 1).

The mean score of health-related quality of life in face-to-face education, educational booklet and control groups was not significantly different before intervention $(\mathrm{P}=0.1, \mathrm{~F}=2.4)$, however after the intervention, the mean score of health-related quality of life in the face-to-face education group was more than the control group, and this difference was statistically significant $(\mathrm{P}=0.001, \mathrm{~F}=18)$. Pair comparison of health-related quality of life mean scores in the intervention groups after intervention showed a significant difference between the face-toface education group and the educational booklet with the control group ( $\mathrm{p}=0.001$; Table 2$)$.

Table 1) The absolute and relative frequency of demographic variables in face-to-face education, educational booklet and control groups (each group with 40 subjects; the numbers are in parenthesis are percentages)

\begin{tabular}{|c|c|c|c|c|}
\hline $\begin{array}{c}\text { Demographic } \\
\text { variables }\end{array}$ & $\begin{array}{l}\text { Face-to- } \\
\text { face } \\
\text { education } \\
\text { group } \\
\end{array}$ & $\begin{array}{c}\text { Educationa } \\
\text { l booklet } \\
\text { group }\end{array}$ & $\begin{array}{l}\text { Control } \\
\text { group }\end{array}$ & $\begin{array}{c}P \\
\text { value }\end{array}$ \\
\hline \multicolumn{5}{|l|}{$\begin{array}{l}\text { Age group, } \\
\text { year }\end{array}$} \\
\hline $30-39$ & $1(2.5)$ & $4(10.0)$ & $5(12.5)$ & 0.08 \\
\hline $40-49$ & 7 (17.5) & $5(12.5)$ & $4(10.0)$ & \\
\hline 50-59 & $21(52.5)$ & $22(55.0)$ & $12(30.0)$ & \\
\hline 60 and over & $11(27.5)$ & $9(22.5)$ & $19(47.5)$ & \\
\hline \multicolumn{5}{|l|}{ Gender } \\
\hline Male & $6(15.0)$ & $(27.5) 11$ & $6(15.0)$ & 0.26 \\
\hline Female & $34(85.0)$ & (72.5) 29 & $(85.0) 34$ & \\
\hline \multicolumn{5}{|l|}{ BMI $\left(\mathrm{kg} / \mathrm{m}^{2}\right)$} \\
\hline$<20$ & $13(32.5)$ & $18(45.0)$ & $19(47.5)$ & 0.02 \\
\hline $20-25$ & $21(52.5)$ & $14(35.0)$ & $18(45.0)$ & \\
\hline $25-30$ & $6(15.0)$ & $8(20.0)$ & $2(5.0)$ & \\
\hline$>30$ & 0 & 0 & $1(2.5)$ & \\
\hline \multicolumn{5}{|l|}{ Marital status } \\
\hline Single & 0 & $1(2.5)$ & $2(5.0)$ & 0.04 \\
\hline Married & $38(95.0)$ & 37 (92.5) & $38(95.0)$ & \\
\hline Other & $2(5.0)$ & $2(5.0)$ & 0 & \\
\hline \multicolumn{5}{|l|}{$\begin{array}{l}\text { History of } \\
\text { diabetes }\end{array}$} \\
\hline No & 11 (27.5) & $14(35.0)$ & $13(32.5)$ & 0.07 \\
\hline Yes & $29(72.5)$ & $26(65.0)$ & 27 (67.5) & \\
\hline \multicolumn{5}{|l|}{$\begin{array}{l}\text { Diagnosis of } \\
\text { diabetes }\end{array}$} \\
\hline Blood test & $25(62.5)$ & $24(60.0)$ & $28(70.0)$ & 0.01 \\
\hline Symptoms & $14(35.0)$ & $11(27.5)$ & $6(15.0)$ & \\
\hline Complications & 0 & $3(7.5)$ & $5(12.5)$ & \\
\hline Other & $1(2.5)$ & $2(5.0)$ & $1(2.5)$ & \\
\hline
\end{tabular}

Table 2) The mean of health-related quality of life scores in patients with type 2 diabetes in the studied groups before and after intervention

\begin{tabular}{lccc}
\hline \multicolumn{1}{c}{ Stages } & $\begin{array}{c}\text { Face-to- } \\
\text { face } \\
\text { education } \\
\text { group }\end{array}$ & $\begin{array}{c}\text { Educational } \\
\text { booklet } \\
\text { group }\end{array}$ & $\begin{array}{c}\text { Control } \\
\text { group }\end{array}$ \\
\hline $\begin{array}{l}\text { Before } \\
\text { intervention }\end{array}$ & $46.60 \pm 8.70$ & $50.90 \pm 9.10$ & $47.82 \pm 9.60$ \\
$\begin{array}{l}\text { After } \\
\text { intervention }\end{array}$ & $59.37 \pm 5.60$ & $57.47 \pm 9.26$ & $48.85 \pm 9.60$ \\
\hline
\end{tabular}


Moreover, in comparison with the control group, there was no significant difference between the mean score of health-related quality of life before and after the intervention $(\mathrm{p}=0.99, \mathrm{~F}=1.7)$, but in the face-to-face education $(\mathrm{t}=1.15)$ and educational booklet $(t=5.26)$, there was a significant increase after intervention $(\mathrm{p}=0.001)$.

\section{Discussion}

Relevant literature review showed that some studies have examined face-to-face education in comparison with other methods, such as computer-based and Internet-based education. Some have studied the combination of face-to-face education with and without educational pamphlets, and a number of studies investigated the effect of face-to-face educational intervention or educational booklet on patients alone and a study comparing these two educational methods in patients with type 2 diabetes was not found. Therefore, the present study compared the effect of face-to-face education and educational booklet on health-related quality of life in patients with type 2 diabetes.

The findings of this study showed that both interventions compared with the control group could improve the health-related quality of life. In other words, the effect of face-to-face education and educational booklet on health-related quality of life was the same. Therefore, nurses as healthcare members caring Type 2 diabetes using both methods, including face-to-face education or educational booklet can play a valuable role in improving their quality of life.

Keulers et al. in a clinical trial study compared whether face-to-face education could replace a computer-based education. The results showed that the use of computer-based education in patients resulted in a higher level of knowledge than the faceto-face education by the physician and this difference was significant. However, it seems that the patients were satisfied with the use of both methods [32]. The findings of this study are not consistent with the present study on the effectiveness of face-to-face education, which may be due to the fact that patients can be trained without a doctor's visit; in addition, they can save time and money for counseling and discussing treatment. Heikkinen et al. also compared the two methods of educational intervention (face-to-face education and internet education) to cognitive empowerment in orthopedic outpatient surgeries and found that both methods led to improvement and advancement in knowledge of patients, and both were significant, although Internet-based education had a greater impact on increasing the level of knowledge of patients [33]. In this study, face-to-face education has had the same effect as the present study. Rantonen et al., similar to the results of the present study, found that the patient's knowledge obtained by face-to-face education plus educational booklet provided by a professional health nurse was not significantly more effective in pain management of the employees with mild back pain in comparison with educational booklet alone [28], which is consistent with the results of this study. Coudeyre et al. also examined the effect of a simple educational booklet on resistant pain after an acute low back pain; the results of this study showed minor improvement [34]. In this study, as in the present study, the effect of educational book on pain control has been shown, but no comparison was made with face-to-face education.

Etemadi Sanandaji et al., in a clinical trial study, examined the effect of face-to-face education and educational booklet on respiratory self-efficacy in patients with chronic obstructive pulmonary disease. The findings of the study showed that the face-to-face education method was more effective than the educational booklet [27], which was not consistent with the findings of the present study. The difference in results can be due to the greater effect of face-to-face education in hospitalized patients in the mentioned study, while the present study was performed on outpatients. Angioli et al. in a randomized study, examined the effect of verbal education (face-to-face) and pre-operative pamphlet in women undergoing oncology surgery. The results showed that the use of pre-operative pamphlet resulted in a faster improvement and reduced hospitalization days, improved information satisfaction, lowered medication consumption, and also caused a better quality of life [35]. In this study, the use of pamphlet can be similar to the booklet in the present study and verbal information has been provided with face-to-face education. In this regard, both studies are similar, but the difference between the two studies is that in this the operation complications have been studied, while in the present study, promotion of quality of life was obtained.

Contrary to the results of this study, in a randomized clinical trial, Bjørnnes et al. concluded that educational intervention by educational booklet did not significantly reduced postoperative pain after an heart surgery compared with the control group [36], which is not consistent with the findings of this study. Although in this study, the effect of training by the brochure may be similar to that of the booklet, but the outcome of the two studies is different in nature. Pain is a pathological problem, while quality of life is related to the physical, psychological and social dimensions of health.

It is very clear that any educational method can result in positive effects with different domains, but the important point in education is selecting the best educational approach for more and more controlling of diseases, for reducing as much complications as possible and ultimately for improving the quality of life of people with chronic diseases [27]. 
The lack of proper cooperation of some patients and a short-term intervention (two weeks) as well as the possibility of communication between the booklet and face-to-face education groups were as the limitations of this study. It is suggested that in future studies, the impact of other educational methods, especially new educational methods such as Internet and computer-based education, on diabetics and other chronic diseases should be considered.

\section{Conclusions}

Face-to-face education and educational booklet intervention can increase the health-related quality of life of interventional groups. Therefore, both educational interventions can be used to train diabetic patients. However, due to the fact that in many situations, because of the limited resources, equipment and manpower, there is no possibility of using face-to-face education, so educational booklet can be used as an alternative.

\section{Acknowledgments}

This study was extracted from a Master's degree thesis (RCT code: IRCT2016112931166N1). The vice-chancellor of Yasuj University of Medical Sciences, who sponsored this research are appreciated. In addition all studied patients are appreciated, as well.

\section{Ethical permissions}

This study approved by the Yasuj University of Medical Sciences Ethics Committee (Ethics code: IR.YUMS.REC.1395.70).

\section{Conflicts of interests}

None declared.

\section{Authors' contribution}

Alikaram Alamdari (first author), main researcher (20\%); Razie Taheri (second author), writing discussion/main researcher (25\%); Ardeshir Afrasiabifar (third author), methodologist/analyst (25\%); Mohammad Latif Rastian (fourth author), writing introduction/writing discussion (30\%).

\section{Funding/Support}

This research was sponsored by the Vice-Chancellor for Research in Yasuj University of Medical Sciences.

\section{References}

1- American Diabetes Association. Diagnosis and classification of diabetes mellitus. Diabetes Care. 2010;33(Suppl 1):S62-9.

2- Bradshaw Kaiser A, Zhang N, Van Der Pluijm W. Global prevalence of type 2 diabetes over the next ten years (2018-2028). Diabetes. 2018;67(Supplement 1):202-LB.

3- Heidari S, Raisi M, Ahmari Tehran H, Khorrami Rad A. Relationship between religious activities and spiritual health with glycemic control in patients with diabetes. Iran J Nurs. 2013;26(81):78-87. [Persian]

4- Tabish SA. Is diabetes becoming the biggest epidemic of the twenty-first century? Int J Health Sci (Qassim). 2007;1(2):5-8.
5- Ahanchi NS, Eslami AA, Sharifirad G. Effects of familybased theory of social support on perceived support levels in type 2 diabetic patients. Health Syst Res. 2012;8(5):757-64. [Persian]

6- Doosti Irani M, Abazari P, Babaei S, Shahgholian N. Facilitators ofadherence to self-management in type 2 diabetic patients: a phenomenological study. Iran J Endocrinol Metab. 2009;11(3):257-64. [Persian]

7- Lewis CP, Newell JN. Patients' perspectives of care for type 2 diabetes in Bangladesh-a qualitative study. BMC Public Health. 2014;14(1):737.

8- Yin Sh, Njai R, Barker L, Siegel PZ, Liao Y. Summarizing health-related quality of life(HRQOL):development and testing of a one-factor model. Popul Health Metr. 2016;14:22.

9- Trikkalinou A, Papazafiropoulou AK, Melidonis A. Type 2 diabetes and quality of life. World J Diabetes. 2017;8(4):120-9.

10- Masror Roudsari D ,Dabiri Golchin M, Parsa yekta Z, Haghani H. Relationship between adherence to therapeutic regimen and health related quality of life in hypertensive patients. Iran J Nurs. 2013;26(85):44-54. [Persian]

11- Palermo TM, Long AC, Lewandowski AS, Drotar D, Quittner AL, Walker LS. Evidence-based assessment of health-related quality of life and functional impairment in pediatric psychology. J Pediatr Psychol. 2008;33(9):98396.

12- Revicki DA, Kleinman L, Cella D. A history of healthrelated quality of life outcomes in psychiatry. Dialogues Clin Neurosci. 2014;16(2):127-35.

13- Grandy S, Fox KM. EQ-5D visual analog scale and utility index values in individuals with diabetes and at risk for diabetes: Findings from the Study to Help Improve Early evaluation and management of risk factors Leading to Diabetes (SHIELD). Health Qual Life Outcomes. 2008;6(1):18.

14- Holmes J, McGill S, Kind P, Bottomley J, Gillam S, Murphy M. Health-related quality of life in type 2 diabetes (TARDIS-2). Value Health. 2000;3(Suppl 1):47-51.

15- Kooshyar H, Shoorvazi M, Dalir Z, Hosseini M. Health literacy and its relationship with medical adherence and health-related quality of life in diabetic communityresiding elderly. J Mazandaran Univ Med Sci. 2014;23(1):133-43. [Persian]

16- Koopmanschap M. Coping with type II diabetes: the patient's perspective. Diabetologia. 2002;45(7):S18-22.

17- Wexler DJ, Grant RW, Wittenberg E, Bosch JL, Cagliero E, Delahanty L, et al. Correlates of health-related quality of life in type 2 diabetes. Diabetologia. 2006;49(7):1489-97. 18- Carbone ET, Campbell MK, Honess-Morreale L. Use of cognitive interview technique in the development of nutrition surveys and interactive nutrition messages for low-income populations. J Am Diet Assoc. 2002;102(5):690-6.

19- Kashfi SM, Khani Jeyhouni A, Bahadori Khalili R, Hatami M. Evaluation of the effects of educating about nutrition and jogging on the blood sugar of type II diabetic patients of a clinic in Shiraz, Iran. Hakim. 2009;12(3):5460. [Persian]

20- Saeidpour J, Jafari M, Ghazi Asgar M, Dayani Dardashti H. Effect of educational program on quality of life in diabetic patients. J Health Adm. 2013;16(52):26-36. [Persian]

21- Shirazi M, Anoosheh M, Rajab A. The effect of self care program education by group discussion method on self 
Comparison of the Impact of Face-to-face Education and Educational ...

concept in diabetic adolescent girls reffered to Iranian Diabetes Society. Iran J Nurs Res. 2011;6(22):40-52. [Persian]

22- Zamanzdeh V, Seyied Rasuli A, Jabbarzadeh F. The effect of empowerment program education on self efficacy in diabetic patients in Tabriz university of medical science diabetes education center. Res J Biol Sci. 2008;3(8):850-5. 23- Vahedian Azimi A, Alhani F, Hedayat K. Barriers and facilitators of patients education nurses perspectives. Nurses' Perspectives. Iran J Med Educ. 2012;11(6):620-34. [Persian]

24- Hekmatpou D, Anoosheh M, Alhani F. Pathology of patient education: a qualitative study. Iran J Nurs. 2007;20(49):51-60. [Persian]

25- Khademian Z, mogharei M, Shokraian N. Comparison of the effect of face to face teaching and the educational booklet on the patient's learning after urologic surgical procedures. J Nurs Educ. 2012;1(1):70-7. [Persian]

26- Noorian K, Rajaei M, Moazeni M, Aein F. Compare the effectiveness of face-to-face education with leaflet on preoperative knowledge of patients undergoing elective surgery- A randomized clinical trial. J Clin Nurs Midwifery. 2013;4(3):1-7. [Persian]

27- Etemadi Sanandaji M, Ghahri Sarabi A, Bonakdar H, Akbarzadeh Baghban A, Banaderakhshan H, Ghasemi S. Comparison of impact of face to face and educational booklet methods on respiratory self efficacy of patients with chronic obstructive pulmonary disease attending to selected hospitals of Shahid Beheshti university of medical sciences in Tehran. J Nurs Educ. 2015;4(1):1-7. [Persian]

28- Rantonen J, Vehtari A, Karppinen J, Luoto S, ViikariJuntura E, Hupli M, Malmivaara A, Taimela S. Face-to-face information combined with a booklet versus a booklet alone for treatment of mild low-ack pain: a randomized controlled trial. Scand J Work Environ Health. 2014;40(2):156-66.
29- Bujang MA, Adnan TH, Mohd Hatta NKB, Ismail M, Lim CJ. A Revised version of diabetes quality of life instrument maintaining domains for satisfaction, impact, and worry. J Diabetes Res. 2018;2018(ID 5804687);1-10.

30- Burroughs TE, Desikan R, Waterman BM, Gilin D, McGill J. Development and validation of the diabetes quality of life brief clinical inventory. Diabetes Spectr. 2004;17(1):41-9.

31- Nasihatkon AA, Phishva AR, Habibzadeh F, Tabatabaei M, Ghashghaeezadeh MT, et al. Determine the reliability and validity of diabetes quality of life- brief clinical inventory in Persian. Iran J Diabetes Metab. 2012;11(5):483-7. [Persian]

32- Keulers BJ, Welters CF, Spauwen PH, Houpt P. Can face-to-face patient education be replaced by computerbased patient education? A randomised trial. Patient Educ Couns. 2007;67(1-2):176-82.

33- Heikkinen K, Helena LK, Taina N, Anne K, Sanna S. A comparison of two educational interventions for the cognitive emprowerment of ambulatory orthopaedic surgery patients. Patient Educ Couns. 2008;73(2):272-9.

34- Coudeyre E, Tubach F, Rannou F, Baron G, Coriat F, Brin S, Revel M, Poiraudeau S. Effect of a simple information booklet on pain persistence after an acute episode of low back pain: a non-randomized trial in a primary care setting. PLoS One. 2007;2(8):e706.

35- Angioli R, Plotti F, Capriglione S, Aloisi A, Aloisi ME, Luvero D, et al. The effects of giving patients verbal or written pre-operative information in gynecologic oncology surgery: a randomized study and the medical-legal point of view. Eur J Obstet Gynecol Reprod Biol. 2014 ;177:6771.

36- Bjørnnes AK, Parry M, Lie I, Fagerland MW, WattWatson J, Rustøen T, et al. The impact of an educational pain management booklet intervention on postoperative pain control after cardiac surgery. Eur J Cardiovasc Nurs. 2017;16(1):18-27. 